\title{
Use of cervical length, measured by transvaginal sonography at 22 to 26 weeks, as a predictor of preterm labour in twin pregnancy
}

\author{
Ricky Saini ${ }^{1}$, Reena Yadav², B. Pathak ${ }^{1 *}$
}

\begin{abstract}
${ }^{1}$ Department of Obstetrics and Gynecology, Command Hospital Air Force, Bangalore, India
${ }^{2}$ Department of Obstetrics and Gynaecology, Lady Hardinge Medical College, New Delhi, India
\end{abstract}

Received: 09 August 2018

Accepted: 13 August 2018

\author{
*Correspondence: \\ Dr. B. Pathak, \\ E-mail: bpathak_go@yahoo.co.in
}

Copyright: ( $)$ the author(s), publisher and licensee Medip Academy. This is an open-access article distributed under the terms of the Creative Commons Attribution Non-Commercial License, which permits unrestricted non-commercial use, distribution, and reproduction in any medium, provided the original work is properly cited.

\begin{abstract}
Background: Preterm labour and delivery contributes significantly to perinatal morbidity and mortality in twin gestation. Measurement of cervical length during antenatal period and subsequent follow up may identify women at risk for preterm labour. The purpose of this study was to determine if measurement of cervical length at 22 to 26 weeks can be used as a predictor of preterm labour in twin pregnancy.

Methods: This prospective observational study was carried out in 50 women with twin gestation in a tertiary care teaching hospital. Cervical length was measured using transvaginal sonography and repeated every four weeks till delivery. Cervical length of $\leq 30 \mathrm{~mm}$ was taken as short cervix and delivery before 37 weeks was taken as preterm delivery.

Results: Total of 18 out of 50 women (36\%) delivered between 32 to 34 weeks, 14 out of 50 (28\%) delivered between 34 to 37 weeks, 7 out of $50(14 \%)$ delivered at less than 32 weeks. Therefore, total preterm deliveries at less than 37 weeks were $78 \%$. Total 11 out of $50(22 \%)$ delivered at term i.e. at more than 37 weeks. In women, who had short cervical length $(\leq 30 \mathrm{~mm})$ at the time of presentation, 14 out of $37(38 \%)$ delivered between 30 to 34 weeks, 12 out of $37(32 \%)$ women delivered between 34 to 37 weeks, 5 out of $37(14 \%)$ delivered at $\leq 30$ weeks. Rest 6 out of $37(16 \%)$ delivered after 37 weeks.

Conclusions: Short cervical length of $\leq 30 \mathrm{~mm}$ on transvaginal sonography at 22-26 weeks of gestation in twin pregnancy may be used as a screening tool in prediction of preterm labour in asymptomatic twin pregnancy.
\end{abstract}

Keywords: Delivery, Gestation, Pregnancy, Preterm, Twin, Transvaginal sonography

\section{INTRODUCTION}

Twin pregnancy is a high-risk pregnancy as it is associated with significant increase in the perinatal and maternal mortality and morbidity.

The major contributing factor to the high perinatal morbidity and mortality associated twin gestation is prematurity. Preterm birth is the most common morbidity associated with twin pregnancies. Survival of preterm infants is mainly dependent on the gestational age at delivery. The ability to identify women at high risk for spontaneous preterm birth could allow for women to undergo targeted interventions such as transfer to tertiary care centre, antenatal corticosteroid administration and tocolysis, which might improve perinatal outcomes among twins.

Transvaginal sonographic cervical length at 20 to 24 weeks gestation is supposed to be a predictor of spontaneous preterm birth in asymptomatic women with twin pregnancies ${ }^{1}$. 
Measurement of cervical length and detection of funneling have been claimed to predict the risk of preterm birth, and increasingly in clinical practice transvaginal ultrasound is being utilized to assess such risk.

Transvaginal ultrasound allows clear and consistently successful visualization of the cervix and the internal os, providing an advantage over transabdominal sonographic evaluation, which may be unreliable due to maternal habitus, position of the cervix, degree of bladder filling, and the obscuring effect of the fetus.

The purpose of this study was to determine if measurement of cervical length at 22 to 26 weeks can be used as a predictor of preterm labour in twin pregnancy.

\section{METHODS}

This prospective observational study was conducted in a tertiary care teaching hospital during November 2011 to March 2013. It comprised of all asymptomatic women with twin pregnancies attending antenatal OPD at 22 to 26 weeks gestation. A detailed transabdominal ultrasound was done before registering them in the study. Presence of any congenital anomalies, prophylactically already given cervical encirclage and abnormal placentation made them ineligible for the study.

All twin pregnancies from 22 weeks to 26 weeks were followed up till delivery. Those women who were induced because of maternal and fetal indications at any time during follow up, were excluded from the study. Ultimately, 50 pregnant women with twin pregnancies were followed up till delivery and included for the study.

After taking informed consent, a detailed history of present and previous pregnancies was taken. Gestational age was based on the last menstrual period and on ultrasound examination report before 20 weeks gestation. After taking a detailed general, systemic and obstetric examination, all ANC investigations were checked and left out investigations were completed. All women were subjected to transabdominal ultrasonography followed by transvaginal scan.

Transvaginal ultrasound examination was performed at 4weekly intervals using $4-9 \mathrm{~Hz}$ vaginal transducer from 22 to 26 weeks gestation till delivery for the purpose of this study. The perinatal outcomes were noted consisting of APGAR Score at 5 minute, NICU admission, early neonatal mortality, perinatal mortality. Statistical analyses were performed using SPSS software, version 12.0 .

\section{RESULTS}

In this study, age of women with twin pregnancy ranged from 19 years to 36 years with majority of woman in age group of 20-25 years (42\%). The mean age was $25.8 \pm 3.8$ years (Table 1).

Table 1: Age distribution of study population.

\begin{tabular}{|lll|}
\hline Age (in yrs) & $\mathbf{N}=50$ & Percentage \\
\hline Less than 20 yrs & 03 & 06 \\
\hline $20-25$ yrs & 21 & 42 \\
\hline $25-30$ yrs & 18 & 36 \\
\hline $30-35$ yrs & 07 & 14 \\
\hline 35 and above & 01 & 02 \\
\hline Mean & 25.8 & \\
\hline S. D. & 3.88 & \\
\hline
\end{tabular}

Majority of the women in our study were multigravida i.e. 34 out of $50(68 \%)$ and in multigravida, second gravida women with twin pregnancy were more common. 39 out of 50 women had spontaneous conception $(78 \%)$ and the rest had induced conception (22\%). 45 women out of 50 had Diamniotic-dichorionic twin pregnancy i.e. $90 \%, 10 \%$ of the women had Diamniotic-monochorionic twins.

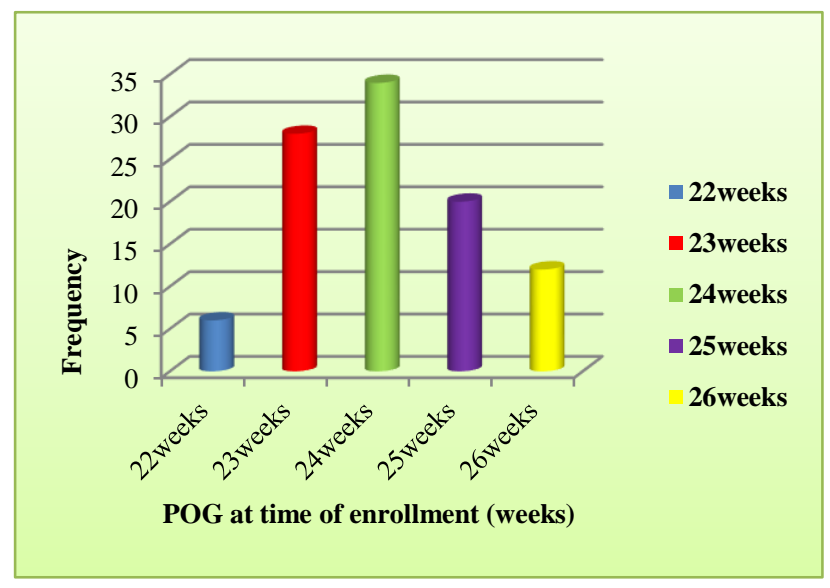

Figure 1: POG at the time of enrolment in study (\%).

Among women with twin pregnancy, majority of the women presented at 24 weeks of period of gestation at the time of enrolment in study i.e. 17 out of 50 (34\%), 14 out of $50(28 \%)$ presented at 23 weeks, 10 out of 50 $(20 \%)$ at 25 weeks, $12 \%$ at 26 weeks and $6 \%$ at 22 weeks. The mean period of gestation at the time of enrolment was $24 \pm 1.58$ weeks (Figure 1).

Table 2: Cervical length at the time of enrollment.

\begin{tabular}{|ll|l|}
\hline Cervical length $(\mathrm{mm})$ & $\mathbf{N}=50$ & Percentage \\
\hline$\leq 30$ & 37 & 74 \\
\hline$\leq 25$ & 11 & - \\
\hline$>25-30$ & 26 & - \\
\hline $31-35$ & 06 & 12 \\
\hline$>35$ & 07 & 14 \\
\hline
\end{tabular}

In the study, majority of women had cervical length $\leq 30$ $\mathrm{mm}$ i.e. 37 out of $50(74 \%), 6$ out of 50 women had 
cervical length between $31-35 \mathrm{~mm}(12 \%)$ and 7 out of 50 women with twin pregnancy had cervical length more than $35 \mathrm{~mm}(14 \%)$ (Table 2).

Table 3: Number of women for 4 weekly serial sonographic scan.

\begin{tabular}{|c|c|c|c|c|c|c|c|c|}
\hline \multirow{3}{*}{$\begin{array}{l}\text { Cervical } \\
\text { length } \\
(\mathbf{m m})\end{array}$} & \multicolumn{8}{|c|}{$\begin{array}{l}\text { Number of women scanned for serial } \\
\text { measurements of cervical length at } 4 \text { - } \\
\text { weeks interval }(\mathrm{N}=50)\end{array}$} \\
\hline & \multicolumn{2}{|c|}{$\begin{array}{l}\text { C1 (at } \\
\text { enrolment) }\end{array}$} & \multicolumn{2}{|l|}{$\mathrm{C} 2$} & \multicolumn{2}{|c|}{ C3 } & \multicolumn{2}{|l|}{ C4 } \\
\hline & $\mathbf{N}$ & $\%$ & $\mathbf{N}$ & $\%$ & $\mathbf{N}$ & $\%$ & $\mathbf{N}$ & $\%$ \\
\hline$\leq 30$ & 37 & 74 & 36 & 72 & 27 & 54 & 06 & 12 \\
\hline $31-35$ & 06 & 12 & 06 & 12 & 04 & 08 & 01 & 02 \\
\hline$>35$ & 07 & 14 & 07 & 14 & 07 & 14 & 04 & 08 \\
\hline Total & 50 & 100 & 49 & 98 & 38 & 72 & 11 & 20 \\
\hline
\end{tabular}

In present study, 37 women out of 50 had cervical length $\leq 30 \mathrm{~mm}(74 \%)$. On follow up scan at 4 weeks interval, the number of women were only $36(72 \%)$ with mean decrease of cervical length at $0.65 \pm 0.77$ per week. One woman had preterm delivery even before the first further follow up. Subsequently, the number of women for scan decreased to $27(54 \%)$ on next follow up scan after 4 weeks with mean decrease in cervical length of $0.48 \pm 0.72$ per week. 9 women had preterm labour before the second follow up scan. Only six women out of $37(12 \%)$ had gone till term when followed with serial ultrasound measurement of cervical length. In contrast, women with cervical length of 31 to $35 \mathrm{~mm}$ and $>35 \mathrm{~mm}$, showed static trend in follow up (Table 3 ).

Table 4: Period of gestation at the time of delivery (in weeks).

\begin{tabular}{lll} 
POG (in weeks) & $\mathbf{N}=50$ & Percentage \\
$\leq 32$ & 7 & 14 \\
\hline$>32-34$ & 18 & 36 \\
$>34-<37$ & 14 & 28 \\
$\geq 37$ & 11 & 22 \\
\hline
\end{tabular}

The period of gestation at the time of delivery in majority of women i.e. 18 out of 50 with twin pregnancy were in between 32 to 34 weeks (36\%), 14 out of 50 delivered between 34 to 37 weeks (28\%), 14\% delivered at less than 32 weeks. Therefore, total preterm deliveries at less than 37 weeks were $78 \%, 22 \%$ delivered at term i.e. at more than 37 weeks (Table 4).

Table 5: Cervical length at presentation and POG at the time of delivery (different cut-off values of cervical length for preterm deliveries).

\begin{tabular}{|c|c|c|c|c|c|c|c|c|c|}
\hline \multirow{2}{*}{$\begin{array}{l}\text { POG at delivery } \\
\text { Cervical length }\end{array}$} & \multicolumn{2}{|c|}{$\leq 30$ weeks $(\mathrm{N}=5)$} & \multicolumn{2}{|c|}{$\begin{array}{l}>30-34 \text { weeks } \\
(\mathrm{N}=19)\end{array}$} & \multicolumn{2}{|c|}{$>34-<37$ weeks $(\mathrm{N}=15)$} & \multicolumn{2}{|c|}{$\geq 37$ weeks $(\mathrm{N}=11)$} & \multirow{2}{*}{ Total } \\
\hline & $\mathbf{N}$ & $\%$ & $\mathbf{N}$ & $\%$ & $\mathbf{N}$ & $\%$ & $\mathbf{N}$ & $\%$ & \\
\hline$\leq 30 \mathrm{~mm}$ & 05 & 14 & 14 & 38 & 12 & 32 & - & - & \\
\hline$\leq 25$ & 02 & 06 & 04 & 11 & 05 & 13 & - & - & 37 \\
\hline$>25-30$ & 03 & 08 & 10 & 27 & 07 & 19 & 06 & 16 & \\
\hline$>30-35 \mathrm{~mm}$ & - & - & 04 & 66 & 01 & 17 & 01 & 17 & 06 \\
\hline$>35 \mathrm{~mm}$ & - & - & 01 & 14 & 02 & 29 & 04 & 57 & 07 \\
\hline
\end{tabular}

Table 6: Sensitivity, specificity, PPV, NPV, accuracy and positive likelihood ratio for different cervical length at various POG.

\begin{tabular}{|c|c|c|c|c|c|c|c|c|c|}
\hline $\begin{array}{l}\text { POG at } \\
\text { delivery }\end{array}$ & $\leq 30$ & & & $\leq 34$ & & & $>34-$ & eeks & \\
\hline $\begin{array}{l}\text { Cervical } \\
\text { length }\end{array}$ & $\begin{array}{l}\leq \mathbf{2 5} \\
\mathbf{m m}\end{array}$ & $\begin{array}{l}\leq 30 \\
\mathbf{m m}\end{array}$ & $\begin{array}{l}\leq 35 \\
\mathbf{m m}\end{array}$ & $\begin{array}{l}\leq 25 \\
\mathbf{m m}\end{array}$ & $\begin{array}{l}\leq \mathbf{3 0} \\
\mathbf{m m}\end{array}$ & $\begin{array}{l}\leq 35 \\
\mathbf{m m}\end{array}$ & $\begin{array}{l}\leq \mathbf{2 5} \\
\mathbf{m m}\end{array}$ & $\begin{array}{l}\leq 30 \\
\mathbf{m m}\end{array}$ & $\begin{array}{l}\leq 35 \\
\mathbf{m m}\end{array}$ \\
\hline Sensitivity (\%) & 40 & 100 & 100 & 40 & 79.7 & 95.8 & 33.3 & 80 & 33.3 \\
\hline Specificity (\%) & 80 & 28.8 & 15.5 & 80.7 & 72.72 & 23.1 & 100 & 45.45 & 80 \\
\hline PPV (\%) & 18.8 & 13.5 & 11.6 & 54.5 & 51.35 & 53.5 & 100 & 66.6 & 50 \\
\hline NPV (\%) & 92.3 & 100 & 100 & 53.8 & 61.5 & 85.7 & 52.3 & 62.5 & 66.6 \\
\hline Accuracy (\%) & 76 & 36 & 24 & 54 & 54 & 58 & 61.5 & 63.4 & 62.5 \\
\hline $\begin{array}{l}\text { Positive likelihood } \\
\text { ratio }\end{array}$ & 2.0 & 1.41 & 1.18 & 1.3 & 1.14 & 1.25 & - & 1.47 & 1.67 \\
\hline
\end{tabular}

In women, who had short cervical length $(\leq 30 \mathrm{~mm})$ at the time of presentation, 14 out of $37(38 \%)$ delivered between >30-34 weeks, 12 out of $37(32 \%)$ women had delivery between $>34-<37$ weeks, 5 out of $37(14 \%)$ delivered at $\leq 30$ weeks. Rest $6 / 37(16 \%)$ delivered after 37 weeks of period of gestation (Table 5 and Table 6). 


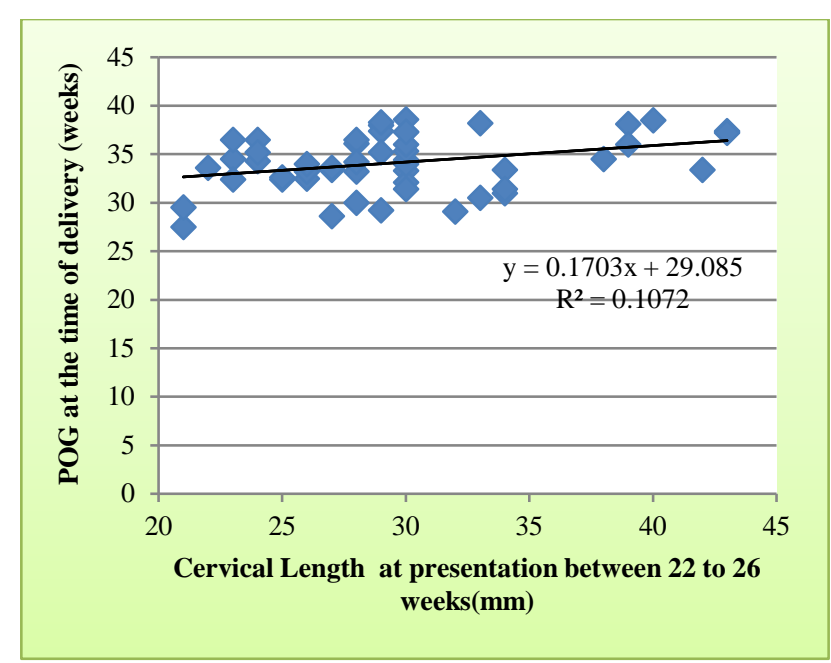

Figure 2: Correlation of cervical length at presentation with POG at delivery.

There is a significant positive correlation between cervical length and period of gestation at delivery and it is $(r=0.3274, \mathrm{p}$-value $=0.02)$.

Even $1 \mathrm{~mm}$ of difference in the cervical length may increase the POG at delivery by 0.1703 weeks $(\approx 1.7$ days). It was seen that there was clustering of preterm deliveries in women with cervical length of $\leq 30 \mathrm{~mm}$ (Figure 2).

Table 7: Association of short cervical length and preterm delivery.

\begin{tabular}{|llll|}
\hline $\begin{array}{l}\text { Outcome } \\
\text { Cervical } \\
\text { length }(\mathrm{mm})\end{array}$ & $\begin{array}{l}\text { Preterm }(<37 \\
\text { weeks })(\mathbf{N})\end{array}$ & $\begin{array}{l}\text { Term }(\geq 37 \\
\text { weeks })(\mathbf{N})\end{array}$ & $\begin{array}{l}\text { Total } \\
(\mathbf{N})\end{array}$ \\
\hline$\leq 30$ & 31 & 06 & 37 \\
\hline$>30$ & 08 & 05 & 13 \\
\hline Total & 39 & 11 & 50 \\
\hline
\end{tabular}

Table 8: Sensitivity, specificity, PPV, NPV, false positivity, false negativity, diagnostic accuracy and pvalue of cervical length and preterm labour.

\begin{tabular}{|l|l|}
\hline Sensitivity & Percentage \\
\hline Specificity & $79.5 \%$ \\
\hline Predictive value of positive test & $45.45 \%$ \\
\hline Predictive value of negative test & $83.80 \%$ \\
\hline$\%$ of false negative & $38.50 \%$ \\
\hline$\%$ of false positive & $20.51 \%$ \\
\hline Diagnostic accuracy & $54.54 \%$ \\
\hline P-value & $72 \%$ \\
\hline
\end{tabular}

In present study, women with twin pregnancy and cervical length of $\leq 30 \mathrm{~mm}$ had statistically significant correlation with preterm delivery ( $<37$ weeks) with a $p$ value of 0.048 . The sensitivity, specificity, positive predictive value, negative predictive value, diagnostic accuracy of test was $79.5 \%, 45.45 \%, 83.8 \%, 38.5 \%, 72 \%$ respectively (Table 7 and Table 8 ).

\section{DISCUSSION}

Maximum number of women had cervical length $\leq 30 \mathrm{~mm}$ i.e. 37 out of $50(74 \%)$. It was found that out of 37 women with cervical length $\leq 30 \mathrm{~mm}, 31$ had preterm delivery $(84 \%)$ and six women had gone till term (16\%).

In a preterm prediction study for risk factors in twin gestation, Goldenberg et al found a cervix $\leq 25 \mathrm{~mm}$ at 24 weeks gestation to be optimal among the best predictors of preterm delivery (O.R. 3.2,95.5 C.I. 1.3-7.9) which they evaluated, including fetal fibronectin and bacterial vaginosis. $^{2}$ They postulated that, for twins, the shortening of the cervix may precede the appearance of increased fibronectin in cervico-vaginal, fluid and that a short cervix most likely develops during the pregnancy rather than before.

In present study, 74\% women had cervical length less than $30 \mathrm{~mm}$ and $86 \%$ had preterm delivery with sensitivity of $79.5 \%$, specificity of $45.45 \%$, positive predictive value of $83.80 \%$, negative predictive value of $38.50 \%$.

These findings are comparable with study conducted by J.M.G. Crane et al at Memorial university of Newfoundland, Canada. ${ }^{3}$ They had taken women with 26 twin pregnancies. They found that endocervical length less than $30 \mathrm{~mm}$ had a sensitivity of $75 \%$, specificity of $30 \%$, positive predictive value of $63 \%$, and negative predictive value of $43 \%$ for twin pregnancies, in predicting spontaneous birth at less than 37 weeks gestation. They concluded that between 23 and 33 weeks gestation, transvaginal ultrasound assessment of endocervical length is superior to funneling and digital examination in predicting preterm delivery in women who present with suspected preterm labour.

In another study, Yang et al, had taken the cut off cervical length as $\leq 30 \mathrm{~mm}$ and found that the sensitivity, specificity, PPV, NPV was 53\%, 90\%, 62\%, 87\% respectively for predicting preterm birth at 35 weeks. ${ }^{4}$ This difference from our study may be due to difference in POG at the time of delivery in our study i.e. $<37$ weeks.

In the study done by Guzman ER, Walters C et al compared various ultrasonographic cervical parameters with respect to ability to predict spontaneous preterm birth in 131 twin gestations and found median gestational age at delivery was 36 weeks gestation (range, 21-41 weeks gestation). ${ }^{5}$ Between 21 and 24 weeks gestation a cervical length of $\leq 2.0 \mathrm{~cm}$ had specificities of $84 \%, 84 \%$, $85 \%$, and $86 \%$ and negative predictive values of $99 \%$, $99 \%, 94 \%$, and $87 \%$ for delivery at $<28,<30,<32$, and $<34$ weeks' gestation, respectively. Between 25 and 28 weeks' gestation cervical length had excellent negative 
predictive values of $99 \%, 98 \%, 95 \%$, and $93 \%$ for delivery at $<28,<30$, <32, and <34 weeks' gestation, respectively. They found that in twin gestations a cervical length of $\leq 2.0 \mathrm{~cm}$ measured between 15 and 28 weeks gestation was at least as good as other ultrasonographic cervical parameters at predicting spontaneous preterm birth.

In the study conducted by Vayssière $\mathrm{C}$ et al on 251 women with twin pregnancies at 22 weeks of gestation and 215 women at 27 weeks of gestation, found that for spontaneous delivery before 32 and 35 weeks of gestation, the sensitivity of cervical length $\leq 30 \mathrm{~mm}$ was $46 \%$ and $27 \%$, respectively; the specificity was $89 \%$ and $90 \%$, respectively. ${ }^{6}$

Sperling $\mathrm{L}$ et al evaluated transvaginal sonographic assessment of cervical length at 23 weeks as a screening test for spontaneous preterm delivery in order to define a cut-off value that could be used to select twin pregnancies at low risk of spontaneous preterm delivery. ${ }^{7}$ In a prospective multicentre study of 383 twin pregnancies included before $14+6$ weeks a cervical scan with measurement of the cervical length was performed at 23 weeks gestation. The rate of spontaneous preterm delivery was $2.3 \%$ (1.5\% for dichorionic (DC) and $9.1 \%$ for (MC) monochorionic twins) before 28 weeks and $18.5 \%$ (17.1\% for DC and $29.5 \%$ for MC twins) before 35 weeks. The screen-positive rate was $5 \%$ for a cervical length $\leq 20,7-8 \%$ at $\leq 25,16-17 \%$ at $\leq 30$ and $34-48 \%$ at $\leq 35 \mathrm{~mm}$ depending on chorionicity. Receiver-operating characteristics curves showed that the sensitivity increased with declining gestational age with cut-off levels of highest accuracy at $21 \mathrm{~mm}$ for 28 weeks and 29 $\mathrm{mm}$ for 33 weeks. They concluded that Cervical length measurement at 23 weeks of gestation is a good screening test for predicting twins at low risk of preterm and very preterm delivery, especially in DC twins.
LIM AC et al did a bivariate meta-analysis in order to review the literature on cervical length as a predictor of preterm birth in asymptomatic women with a multiple pregnancy. ${ }^{8}$ They found 21 studies reporting on 2757 women. There was a large variation in gestational age at measurement, cut-off point for cervical length and definition of preterm birth. Summary estimates of sensitivity and specificity for preterm birth before 34 weeks gestation were $78 \%$ and $66 \%$, respectively, for 35 $\mathrm{mm}, 41 \%$ and $87 \%$ for $30 \mathrm{~mm}, 36 \%$ and $94 \%$ for $25 \mathrm{~mm}$ and $30 \%$ and $94 \%$ for $20 \mathrm{~mm}$. They concluded that in women with a multiple pregnancy, second-trimester cervical length is a strong predictor of preterm birth. Comparison of various studies is given in Table 7. In present study, the sensitivity, specificity, PPV, NPV of transvaginal ultrasound in predicting spontaneous preterm labour in women with cervical length less than $30 \mathrm{~mm}$ was $79.5 \%, 45.45 \%, 83 \%, 38.5 \%$. This finding was comparable to the study conducted by J.M.G. Crane et al in which they found sensitivity, specificity, PPV and NPV of $75 \%, 30 \%, 63 \%, 43 \%$ respectively in women with cervical length of $30 \mathrm{~mm}$ and preterm delivery before 37 weeks. $^{3}$ While in another study done by Vayssiere et al, the sensitivity and specificity were $27 \%$ and $90 \%$ respectively in women with cut-off cervical length of $30 \mathrm{~mm}$ and preterm delivery before 35 weeks and this difference may be due to difference in period of gestation defining preterm delivery i.e. <37 weeks in present study versus preterm delivery before 35 weeks in the study by Vayssiere. ${ }^{6}$

Majority of the studies conducted previously, has taken the cut-off cervical length as $\leq 25 \mathrm{~mm}$. In present study, 11 out of 50 women with twin pregnancy had cervical length of $\leq 25 \mathrm{~mm}$, with that the sensitivity and specificity was $28.2 \%$ and $100 \%$ respectively. These findings were comparable to the study conducted by Sperling et al with sensitivity and specificity of $21.4 \%$ and $96.4 \%$ respectively. ${ }^{7}$ In another study done by Gibson et al found the sensitivity of $29 \%$ and $95 \%$ of specificity. ${ }^{9}$

Table 9: Comparison of predictive value of cervical length with previously published studies.

\begin{tabular}{|llllllll|}
\hline Study (Author) & N & $\begin{array}{l}\text { CL } \\
(\mathbf{m m})\end{array}$ & $\begin{array}{l}\text { GA } \\
\text { (weeks) }\end{array}$ & $\begin{array}{l}\text { Sensitivity } \\
(\%)\end{array}$ & $\begin{array}{l}\text { Specificity } \\
(\%)\end{array}$ & $\begin{array}{l}\text { PPV } \\
(\%)\end{array}$ & NPV $(\%)$ \\
\hline Goldenberg et al & 147 & $\leq 25$ & 24 & 53.8 & 85.8 & 26.9 & 95.0 \\
\hline J.M.G. Crane et al & 26 & $<30$ & 23 to 33 & 75 & 30 & 63 & 43 \\
\hline Yang et al & 65 & $\leq 30$ & 18 to 26 & 53 & 90 & 62 & 87 \\
\hline Guzman et al & 131 & $\leq 20$ & 21 to 24 & 42.0 & 85 & 22.0 & 94 \\
\hline Vayssiere et al & 251 & $\leq 25$ & 22 & 54 & 87 & 38 & 96 \\
\hline Sperling et al & 215 & $\leq 30$ & 27 & 27 & 96.4 & 27.8 & 95.4 \\
\hline Skentou et al & 383 & $\leq 20$ & 23 & 21.4 & 91.8 & 26.7 & 94.3 \\
\hline Present study & 434 & $\leq 25$ & 22 to 24 & 35.3 & 45.45 & 83 & 38.5 \\
\hline
\end{tabular}


In present study, we had taken the cut- off of $\leq 30 \mathrm{~mm}$. The high sensitivity demonstrates that role of transvaginal ultrasound as a screening tool for prediction of spontaneous preterm labour in women with short cervical length $(\leq 30 \mathrm{~mm})$. Serial cervical length measurements on transvaginal ultrasound in women at high risk i.e. with short cervical length, will help to individualize management, prevent unnecessary hospitalization and obstetric intervention, and improve perinatal outcome by optimizing the timing of antenatal steroid therapy and transfer to a tertiary care centre.

\section{CONCLUSION}

Short cervical length of $\leq 30 \mathrm{~mm}$ on transvaginal sonography at 22-26 weeks of gestation in twin pregnancy may be used as a screening tool in prediction of preterm labour in asymptomatic twin pregnancy. Shorter the cervical length, earlier is the preterm delivery in women with twin pregnancy.

Funding: No funding sources Conflict of interest: None declared

Ethical approval: The study was approved by the Institutional Ethics Committee

\section{REFERENCES}

1. Agustin Conde-Agudelo A, Romero R, Hassan SS, Yeo L. Transvaginal sonographic cervical length for the prediction of spontaneous preterm birth in twin pregnancies: a systematic review and metanalysis. Am J Obstet Gynecol. 2010;203(2):128.

2. Goldenberg RL, Iams JD, Miodovnik M, Van Dorsten JP, Thurnau G, Bottoms S et al. The preterm prediction study: risk factors in twin gestations. National Institute of Child Health and Human Development Maternal-Fetal Medicine Units Network. Am J Obstet Gynecol. 1996;175:1047-53.

3. Crane JMG, Van den Hof F, Armson BA, Liston R. Transvaginal ultrasound in the prediction of preterm delivery: Singleton and twin gestations. Obstet Gynecol. 1997;90:357-63.
4. Yang JH, Kuhlman K, Daly S, Berghella V. Prediction of preterm birth by second trimester cervical sonography in twin pregnancies. Ultrasound Obstet Gynecol. 2000;15:288-91.

5. Guzman ER, Walters C, O'Reilly-Green C, Kinzler WL, Waldron R, Nigam $J$ et al. Use of cervical ultrasonography in prediction of spontaneous preterm birth in twin gestations. Am J Obstet Gynecol. 2000;183:1103-7.

6. Vayssiere C, Favre R, Audibert F, Chauvet MP, Gaucherand P, Tardif et al. Cervical length and funneling at 22 and 27 weeks to predict spontaneous birth before 32 weeks in twin pregnancies: a French prospective multicenter study. Am J Obstet Gynecol. 2002;187:1596-604.

7. Sperling L, Kiil C, Larsen LU, Qvist I, Bach D, Wojdemann K, et al. How to identify twins at low risk of spontaneous preterm delivery. Ultrasound Obstet Gynecol. 2005;26:138-44.

8. Lim AC, Hegeman MA, Huis In 'T Veld MA, Opmeer BC, Bruinse HW, Mol BW. Cervical length measurement for the prediction of preterm birth in multiple pregnancies: a systematic review and bivariate meta-analysis. Ultrasound Obstet Gynecol. 2011;38(1):10-7.

9. Gibson JL, Macara LM, Owen P, Young D, Macauley J, Mackenzie F. Prediction of preterm delivery in twin pregnancy: a prospective, observational study of cervical length and fetal fibronectin testing. Ultrasound Obstet Gynecol. 2004; 3(6):561-6.

10. Skentou C, Souka AP, To MS, Liao AW, Nicolaides KH. Prediction of preterm delivery in twins by cervical assessment at 23 weeks. Ultrasound Obstet Gynecol. 2001;17:7-10.

Cite this article as: Saini R, Yadav R, Pathak B. Use of cervical length, measured by transvaginal sonography at 22 to 26 weeks, as a predictor of preterm labour in twin pregnancy. Int J Reprod Contracept Obstet Gynecol 2018;7:3590-5. 